\title{
Article \\ Acceptance of COVID-19 Vaccines among Patients with Inflammatory Bowel Disease in Japan
}

\author{
Yu Nishida (D), Shuhei Hosomi *(D), Yumie Kobayashi, Rieko Nakata, Masaki Ominami, Yuji Nadatani (D), \\ Shusei Fukunaga (D), Koji Otani (D), Fumio Tanaka, Yasuaki Nagami, Koichi Taira, Noriko Kamata \\ and Yasuhiro Fujiwara
}

check for

updates

Citation: Nishida, Y.; Hosomi, S.;

Kobayashi, Y.; Nakata, R.; Ominami, M.; Nadatani, Y.; Fukunaga, S.; Otani, K.; Tanaka, F.; Nagami, Y.; et al. Acceptance of COVID-19 Vaccines among Patients with Inflammatory Bowel Disease in Japan. Healthcare 2022, 10, 6. https://doi.org/ 10.3390/healthcare10010006

Academic Editor: Atsushi Irisawa

Received: 4 November 2021

Accepted: 17 December 2021

Published: 22 December 2021

Publisher's Note: MDPI stays neutral with regard to jurisdictional claims in published maps and institutional affiliations.

Copyright: (C) 2021 by the authors. Licensee MDPI, Basel, Switzerland. This article is an open access article distributed under the terms and conditions of the Creative Commons Attribution (CC BY) license (https:// creativecommons.org/licenses/by/ $4.0 /)$.
Department of Gastroenterology, Osaka City University Graduate School of Medicine, Osaka 545-8585, Japan; m2076030@med.osaka-cu.ac.jp (Y.N.); yumie-koba@ktd.biglobe.ne.jp (Y.K.); m1310984@med.osaka-cu.ac.jp (R.N.); ominami@med.osaka-cu.ac.jp (M.O.); dada@med.osaka-cu.ac.jp (Y.N.); m1156849@med.osaka-cu.ac.jp (S.F.); kojiotani@med.osaka-cu.ac.jp (K.O.); m2079981@med.osaka-cu.ac.jp (F.T.); yasuaki-75@med.osaka-cu.ac.jp (Y.N.); koichit@med.osaka-cu.ac.jp (K.T.); m1266151@med.osaka-cu.ac.jp (N.K.); yasu@med.osaka-cu.ac.jp (Y.F.)

* Correspondence: m1265271@med.osaka-cu.ac.jp; Tel.: +81-6-6645-3811

Abstract: Coronavirus disease 2019 (COVID-19) vaccination is recommended for patients with inflammatory bowel disease (IBD). However, the acceptance of COVID-19 vaccines has not been sufficiently evaluated in patients with IBD. We aimed to assess the acceptance and hesitancy of COVID-19 vaccination and related factors among these patients. A retrospective cohort study using a self-reported questionnaire was performed among patients with IBD between 22 June 2021 and 30 August 2021. Of the 187 participants, $10.2 \%(n=19)$ were hesitant to be vaccinated. Patients in the vaccine-hesitant group were younger $(p=0.009)$ and had a shorter disease duration $(p=0.020)$. Vedolizumab was prescribed more frequently $(p=0.024)$ and immunomodulators were less frequently used ( $p=0.027$ ) in this group. Multivariable logistic regression analysis identified age (odds ratio [OR]: $0.96,95 \%$ confidence interval [CI]: $0.92-1.00, p=0.042)$ and the use of immunomodulators (OR: $0.08,95 \%$ CI: $0.01-0.66, p=0.019$ ) as independent significant factors for vaccine hesitancy. The COVID-19 vaccine hesitancy rate in patients with IBD in Japan was $10 \%$ in this study. The Japanese COVID-19 vaccination campaign appears to be successful. The risk of COVID-19 among patients with IBD requires adequate measures to ensure that vaccines are accepted by vaccine-hesitant patients. These findings may be helpful in achieving adequate vaccination rates.

Keywords: surveys and questionnaires; severe acute respiratory syndrome coronavirus 2; mRNA1273; BNT162b2; AZD1222

\section{Introduction}

Coronavirus disease 2019 (COVID-19), caused by severe acute respiratory syndrome coronavirus 2 (SARS-CoV-2), emerged in Wuhan, China, in December 2019 and the outbreak rapidly spread worldwide [1]. Vaccines are authorized and recommended to prevent COVID-19 because of their high safety and efficacy [2,3]. The presence of a vaccine is a key element to prevent COVID-19, and therefore, to minimize new infections. It is crucial to vaccinate people to prevent the spread of COVID-19 [3]. In Japan, the COVID-19 vaccination campaign for older individuals started in April 2021, followed by people with underlying diseases, and then the rest of the general population. At the time of this survey, three vaccines against COVID-19 have been approved in Japan: mRNA-1273 (Moderna, Cambridge, MA, USA), BNT162b2 (Pfizer/BioNTech, New York, NY, USA), and AZD1222 (AstraZeneca, Cambridge, UK). However, vaccine hesitancy remains high even in the COVID-19 pandemic period [4]. The COVID-19 vaccine hesitancy rate was reported to be $20 \%$ (13-29\%) among ordinary people in a systematic review [5]. In Japan, 11.0 to $12.3 \%$ of the general population are unwilling to be vaccinated [6-8]. Previous studies have reported that COVID-19 vaccine hesitancy is associated with sex, young age, living alone, 
low income, presence of severe psychological distress, region, intention to be vaccinated against influenza in the past year, and a low education level [5,8-14].

Inflammatory bowel disease (IBD), namely ulcerative colitis and Crohn's disease, are intestinal disorders [15-19]. During the course of the disease, the majority of the patients with IBD need long-term immunomodulatory therapies and thus, have an increased risk of infectious diseases $[20,21]$. Patients with IBD are influenced by the lifestyle changes caused by the appearance of COVID-19 [22,23].

A low acceptance rate of vaccination was reported in a systematic review among patients with IBD, ranging from $11 \%$ to $54 \%$ [24]. Regarding COVID-19, IBD itself does not increase the risk of developing the disease [25]. Therefore, clinical guidelines recommend that patients should continue current IBD medications [26,27]. The incidence of adverse events of special interest in IBD patients after COVID-19 vaccination was low and similar to that of a matched cohort of patients without IBD [28]. This includes patients on immunosuppressive agents. The benefits of COVID-19 vaccination in patients with IBD probably outweigh the minimal risk [28]. Furthermore, current studies suggested that systemic corticosteroids might increase the risk of hospitalization, as well as the risk of requiring ventilation, intensive care unit care, and death among patients with immunemediated inflammatory disease $[29,30]$. Patients with IBD are at risk of using steroids, which may lead to aggravation of COVID-19. Therefore, vaccination of patients with IBD should be a higher priority than vaccination of members of the general public. The International Organization for the Study of Inflammatory Bowel Disease and British Society of Gastroenterology recommended vaccinating all patients with IBD as soon as they were able to receive the vaccination, regardless of immune-modifying therapies [31,32]. The International Organization for the Study of Inflammatory Bowel Disease and British Society of Gastroenterology stated that the benefits of vaccination are likely to outweigh these theoretical concerns, even in patients treated with antitumor necrosis factor (TNF) drugs, and that the risks of COVID-19 vaccination in patients with IBD are anticipated to be very low. They recommend that patients with IBD accept whichever approved COVID-19 vaccination is offered to them. Immunosuppressive therapies have been reported to reduce the effectiveness of vaccines. Immunomodulatory therapies, which are often used for IBD patients, have been reported to result in an attenuated vaccine response [33-35]. Vedolizumab is an anti-integrin monoclonal antibody directed against $\alpha 4 \beta 7$ integrin. It has a low incidence rate of serious infection, and it would not affect the vaccine response in healthy controls [36,37]. Anti-SARS-CoV-2 antibody concentrations were higher in patients with vedolizumab therapy compared with patients with infliximab therapy who received COVID-19 vaccination [38]. The combination of anti-TNF with immunomodulators (azathioprine, 6-meracptopurine, methotrexate) resulted in an attenuated vaccine response as compared to anti-TNF monotherapy [33].

Regarding COVID-19 vaccinations among patients with IBD, 17.7\% were hesitant to be vaccinated in an Italian survey [39], 24.0\% in a French survey [40], and $14 \%$ in a Spanish survey [41]. Some studies have reported the acceptance of COVID-19 vaccines; however, different studies have had conflicting results, and no studies have reported the acceptance of COVID-19 vaccines in Japan [42]. Consequently, there is an urgent need for an understanding of current attitudes toward vaccines and factors determining vaccine intent in patients with IBD in Japan.

Therefore, we aimed to explore hesitancy toward, and acceptance of, COVID-19 vaccines in patients with IBD and to identify factors associated with these attitudes, including consideration of participants' background, lifestyle, disease condition, medication, and the presence of other people in the household. 


\section{Materials and Methods}

\subsection{Study Design and Participants}

This was a retrospective cohort study using a questionnaire among patients with IBD ( $\geq 16$ years old) who attended regular follow-up at Osaka City University Hospital from 22 June 2021 to 30 August 2021. We asked patients with IBD who visited our hospital to voluntarily answer the questionnaire. The data were collected anonymously.

\subsection{Exclusion Criteria}

The exclusion criteria were a diagnosis of IBD within the previous 3 months; an inability to complete the questionnaire, despite assistance; and lack of consent.

\subsection{Questionnaire Design}

A self-administered questionnaire was developed based on past literature on similar topics [42-44]. The questionnaire included questions regarding the patient's demographic data (sex, age at recruitment, and age at disease diagnosis), epidemiological history of COVID-19, gastrointestinal symptoms, current medication use, history of COVID-19 vaccination, intention to be vaccinated against COVID-19, and reasons for acceptance or refusal of such vaccination (Table S1). Additionally, the questionnaire included questions about factors that have been reported to be associated with COVID-19 vaccination hesitancy, such as cohabitation status, smoking status, and comorbidities [5,8-12]. After providing online consent, participants completed several questionnaires using the secure Research Electronic Data Capture (REDCap) platform. Participants used a personal computer or smart phone with a complete survey [45] and completed the survey at their convenience so that they could answer the questionnaire without worrying about time.

\subsection{Ethical Considerations}

All participants had to provide their consent before they proceeded to the questionnaire response page, and the Ethics Review Board of Osaka City University Graduate School of Medicine approved this study (no. 2021-102). The questionnaires were made anonymous to ensure patient privacy.

\subsection{Statistical Analysis}

Continuous variables are summarized as medians and interquartile ranges. Clinical characteristics between the vaccinated and those not intending to be vaccinated were compared using either the chi-square test or Fisher's exact test for categorical variables and the Mann-Whitney U-test for continuous variables. We used univariate logistic regression analyses to calculate unadjusted odds ratios of factors associated with vaccine hesitancy. Further, those factors presumed to be risk factors for vaccine hesitancy were then quantified using multivariable analysis with factors exhibiting statistical significance in the univariate analysis and factors reported to be associated with vaccine hesitancy.

Statistical significance was set at $p<0.05$. All statistical analyses were performed with EZR (Saitama Medical Center, Jichi Medical University), a graphical user interface for R (The R Foundation for Statistical Computing, version 2.13.0).

\section{Results}

\subsection{Study Participants}

During this period, 187 patients with IBD were included. The demographic and IBD characteristics of the study population are presented in Table 1. 
Table 1. Sociodemographic characteristics of the study participants by COVID-19 vaccination intention.

\begin{tabular}{|c|c|c|c|c|}
\hline & All Patients & $\begin{array}{l}\text { Willing to Be } \\
\text { Vaccinated }\end{array}$ & $\begin{array}{l}\text { Hesitant to Be } \\
\text { Vaccinated }\end{array}$ & $p$-Value \\
\hline \multicolumn{5}{|l|}{ Demographics } \\
\hline Number of patients & 187 & 168 & 19 & \\
\hline Disease type & & & & 0.221 \\
\hline Ulcerative colitis & $107(57.2 \%)$ & 99 (58.9\%) & $8(42.1 \%)$ & \\
\hline Crohn's disease & $80(42.8 \%)$ & $69(41.1 \%)$ & $11(57.9 \%)$ & \\
\hline Sex & & & & 0.454 \\
\hline Male & $120(64.2 \%)$ & $106(63.1 \%)$ & $14(73.7 \%)$ & \\
\hline Female & $67(35.8 \%)$ & $62(36.9 \%)$ & $5(26.3 \%)$ & \\
\hline $\begin{array}{c}\text { Age at enrollment } \\
\text { (years), median (IQR) }\end{array}$ & $45.0(32.5-56.5)$ & $46.0(34.8-58.3)$ & $32.0(29.5-43.5)$ & 0.009 \\
\hline $\begin{array}{l}\text { Age at diagnosis (years), } \\
\text { median (IQR) }\end{array}$ & $26.0(20.0-40.0)$ & $26.0(20.0-40.0)$ & $24.0(19.0-27.5)$ & 0.185 \\
\hline $\begin{array}{c}\text { Disease duration (years), } \\
\text { median (IQR) }\end{array}$ & $13.0(6.0-22.0)$ & $13.0(7.0-23.3)$ & $6(5-13.5)$ & 0.020 \\
\hline Smoking & & & & 0.324 \\
\hline Yes & $31(16.5 \%)$ & $26(15.5 \%)$ & $5(26.3 \%)$ & \\
\hline No & $156(83.4 \%)$ & $142(84.5 \%)$ & $14(73.7 \%)$ & \\
\hline Drinking & & & & 0.801 \\
\hline Yes & 82 & 73 & 9 & \\
\hline No & 105 & 95 & 10 & \\
\hline \multicolumn{5}{|l|}{ Occupation } \\
\hline Worker & 97 (51.9\%) & $86(51.2 \%)$ & $11(57.9 \%)$ & 0.634 \\
\hline Office worker & $64(34.2 \%)$ & $59(35.1 \%)$ & $5(26.3 \%)$ & 0.611 \\
\hline Health worker & $13(7.0 \%)$ & $10(6.0 \%)$ & $3(15.8 \%)$ & 0.132 \\
\hline Sales assistant & $4(2.1 \%)$ & $4(2.4 \%)$ & $0(0 \%)$ & $>0.999$ \\
\hline Education & $3(1.6 \%)$ & $3(1.8 \%)$ & $0(0 \%)$ & $>0.999$ \\
\hline Delivery person & $3(1.6 \%)$ & $3(1.8 \%)$ & $0(0 \%)$ & $>0.999$ \\
\hline Housemaker & $26(13.9 \%)$ & $24(14.3 \%)$ & $2(10.5 \%)$ & $>0.999$ \\
\hline Student & $10(5.3 \%)$ & $8(4.8 \%)$ & $2(10.5 \%)$ & 0.269 \\
\hline \multicolumn{5}{|l|}{ Cohabitation } \\
\hline $\begin{array}{l}\text { Living with older } \\
\text { individuals }\end{array}$ & $54(28.9 \%)$ & $52(31.0 \%)$ & $2(10.5 \%)$ & 0.067 \\
\hline Living with children & $58(31.0 \%)$ & $5331.5(\%)$ & $526.3(\%)$ & 0.796 \\
\hline $\begin{array}{l}\text { Living with persons } \\
\text { with comorbidities }\end{array}$ & $45(24.1 \%)$ & $42(25.0 \%)$ & $3(15.8 \%)$ & 0.572 \\
\hline \multicolumn{5}{|l|}{ Comorbidity } \\
\hline Hypertension & $23(12.3 \%)$ & $23(13.7 \%)$ & $0(0 \%)$ & 0.136 \\
\hline Cardiac disorder & $0(0 \%)$ & $0(0 \%)$ & $0(0 \%)$ & $\cdots$ \\
\hline $\begin{array}{l}\text { Chronic Obstructive } \\
\text { Pulmonary Disease }\end{array}$ & $0(0 \%)$ & $0(0 \%)$ & $0(0 \%)$ & $\cdots$ \\
\hline Diabetes mellitus & $4(2.1 \%)$ & $4(2.4 \%)$ & $0(0 \%)$ & $>0.999$ \\
\hline Bronchial asthma & $2(1.1 \%)$ & $2(1.2 \%)$ & $0(0 \%)$ & $>0.999$ \\
\hline Hepatic disorder & $5(2.7 \%)$ & $5(3.0 \%)$ & $0(0 \%)$ & $>0.999$ \\
\hline Renal disorder & $7(3.7 \%)$ & $7(4.2 \%)$ & $0(0 \%)$ & $>0.999$ \\
\hline Psychiatric disorder & $16(8.6 \%)$ & $15(8.9 \%)$ & $1(5.3 \%)$ & $>0.999$ \\
\hline
\end{tabular}


Table 1. Cont.

\begin{tabular}{ccccc}
\hline & All Patients & $\begin{array}{c}\text { Willing to Be } \\
\text { Vaccinated }\end{array}$ & $\begin{array}{c}\text { Hesitant to Be } \\
\text { Vaccinated }\end{array}$ & $p$-Value \\
\hline $\begin{array}{c}\text { Medication } \\
\text { Mesalamine }\end{array}$ & $127(67.9 \%)$ & $113(67.3 \%)$ & $14(73.7 \%)$ & 0.796 \\
$\begin{array}{c}\text { Corticosteroids } \\
\text { Immunomodulators }\end{array}$ & $18(9.6 \%)$ & $15(8.9 \%)$ & $3(15.8 \%)$ & 0.402 \\
$\begin{array}{c}\text { (azathioprine or } \\
\text { 6-mercaptopurine) }\end{array}$ & $52(27.8 \%)$ & $51(30.4 \%)$ & $1(5.3 \%)$ & 0.027 \\
Anti-TNF & $50(26.7 \%)$ & $44(26.2 \%)$ & $6(31.6 \%)$ & 0.593 \\
Ustekinumab & $23(12.3 \%)$ & $19(11.3 \%)$ & $4(21.1 \%)$ & 0.261 \\
Vedolizumab & $7(3.7 \%)$ & $4(2.4 \%)$ & $3(15.8 \%)$ & 0.024 \\
Tofacitinib & $4(2.1 \%)$ & $4(2.4 \%)$ & $0(0 \%)$ & $>0.999$ \\
\hline $\begin{array}{c}\text { COVID-19 } \\
\text { COVID-19 contact }\end{array}$ & $4(2.1 \%)$ & $4(2.4 \%)$ & $0(0 \%)$ & $>0.999$ \\
COVID-19 isolation & $4(2.1 \%)$ & $4(2.4 \%)$ & $0(0 \%)$ & $>0.999$ \\
COVID-19 infection & $2(1.1 \%)$ & $2(1.2 \%)$ & $0(0 \%)$ & $>0.999$ \\
\hline
\end{tabular}

COVID-19, coronavirus disease 2019; IQR, interquartile range; TNF, tumor necrosis factor.

\subsection{Assessment of COVID-19 Vaccination Hesitancy}

Of the participants, $17.1 \%(n=32)$ intended to be vaccinated, $24.6 \%(n=46)$ had been vaccinated once, $48.1 \%(n=90)$ had completed two vaccinations, and $10.2 \%(n=19)$ were hesitant to be vaccinated (Figure 1).

\section{Hesitant to be vaccinated}

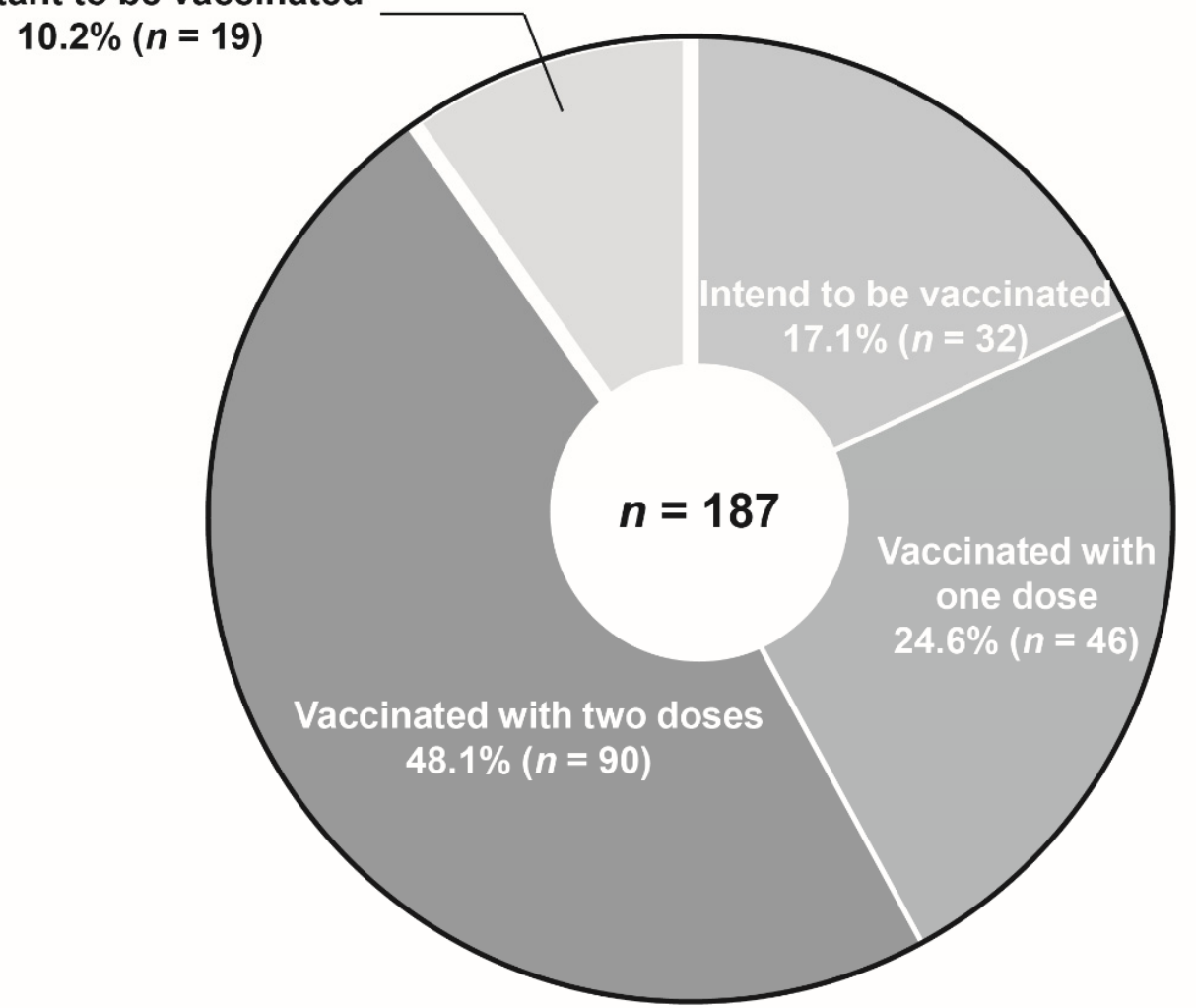

Figure 1. Willingness and hesitancy of patients with inflammatory bowel disease to receive a coronavirus disease 2019 vaccine. 


\subsection{Factors Associated with Vaccine Hesitancy}

Patients in the vaccine-hesitant group were younger $(p=0.009)$ and had shorter IBD disease duration $(p=0.020)$. Patients who were hesitant to be vaccinated were more likely to be on treatment with vedolizumab $(p=0.024)$ and were less likely to be using immunomodulators (azathioprine or 6-mercaptopurine) $(p=0.027)$. Patients who were willing to be vaccinated were more likely to live with an older person (Table 1).

The patients' sociodemographic factors were analyzed to identify factors associated with vaccine hesitancy. From the univariate logistic regression analysis, vaccine hesitancy exhibited a significant relationship with age (OR: $0.96,95 \%$ CI: $0.92-0.99, p=0.011$ ), the use of immunomodulators (OR: $0.13,95 \%$ CI: $0.02-0.98, p=0.048$ ), and the use of vedolizumab (OR: 7.69, 95\% CI: 1.58-37.40, $p=0.012$ ). Multivariable logistic regression analysis was performed to identify the factors related to vaccine hesitancy. Variables in the multivariate analysis were selected among factors exhibiting statistical significance in the univariate analysis and factors reported to be associated with vaccine hesitancy: sex, age at enrollment, disease duration, living with older individuals, use of immunomodulators and use of vedolizumab [5,8-14]. In the multivariable analysis, age (OR: 0.96, 95\% CI: 0.92-1.00, $p=0.042$ ) and the use of immunomodulators (OR: $0.08,95 \%$ CI: $0.01-0.66, p=0.019$ ) was significantly associated with vaccine hesitancy (Table 2). Younger age was positively associated with COVID-19 vaccine hesitancy, whereas the use of immunomodulators was negatively associated with vaccine hesitancy.

Table 2. Univariate and multivariable logistic regression analysis of hesitancy toward COVID19 vaccination.

\begin{tabular}{|c|c|c|c|c|}
\hline & $\begin{array}{c}\text { Unadjusted OR } \\
(95 \% \mathrm{CI})\end{array}$ & $p$-Value & $\begin{array}{l}\text { Adjusted OR } \\
(95 \% \mathrm{CI})\end{array}$ & $p$-Value \\
\hline \multicolumn{5}{|l|}{ Demographics } \\
\hline \multicolumn{5}{|l|}{ Disease type } \\
\hline Ulcerative colitis & Ref. & & & \\
\hline Crohn's disease & $1.97(0.75-5.16)$ & 0.166 & & \\
\hline \multicolumn{5}{|l|}{ Sex } \\
\hline Male & Ref. & & Ref. & \\
\hline Female & $0.61(0.21-1.78)$ & 0.365 & $0.38(0.11-1.31)$ & 0.126 \\
\hline Age at enrollment & $0.96(0.92-0.99)$ & 0.011 & $0.96(0.92-1.00)$ & 0.042 \\
\hline Age at diagnosis & $0.97(0.93-1.01)$ & 0.171 & & \\
\hline Disease duration & $0.95(0.90-1.00)$ & 0.056 & $0.98(0.92-1.05)$ & 0.477 \\
\hline \multicolumn{5}{|l|}{ Smoking } \\
\hline No & Ref. & & & \\
\hline Yes & $1.95(0.65-5.88)$ & 0.235 & & \\
\hline \multicolumn{5}{|l|}{ Alcohol consumption } \\
\hline Non-drinker & Ref. & & & \\
\hline Drinker & $0.71(0.15-3.25)$ & 0.655 & & \\
\hline \multicolumn{5}{|l|}{ Occupation } \\
\hline \multirow{2}{*}{\multicolumn{5}{|c|}{ Worker }} \\
\hline & & & & \\
\hline Yes & $1.31(0.50-3.42)$ & 0.580 & & \\
\hline Office worker & & & & \\
\hline
\end{tabular}


Table 2. Cont.

\begin{tabular}{|c|c|c|c|c|}
\hline & $\begin{array}{c}\text { Unadjusted OR } \\
(95 \% \mathrm{CI})\end{array}$ & $p$-Value & $\begin{array}{c}\text { Adjusted OR } \\
(95 \% \mathrm{CI})\end{array}$ & $p$-Value \\
\hline No & Ref. & & & \\
\hline Yes & $0.66(0.23-1.92)$ & 0.446 & & \\
\hline \multicolumn{5}{|c|}{ Health worker } \\
\hline No & Ref. & & & \\
\hline Yes & $2.96(0.74-11.90)$ & 0.125 & & \\
\hline \multicolumn{5}{|c|}{ Housemaker } \\
\hline No & Ref. & & & \\
\hline Yes & $0.71(0.15-3.25)$ & 0.655 & & \\
\hline \multicolumn{5}{|c|}{ Student } \\
\hline No & Ref. & & & \\
\hline Yes & $2.35(0.46-12.0)$ & 0.303 & & \\
\hline
\end{tabular}

\section{Cohabitation \\ Living with \\ older}

individuals

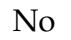

Yes

Ref.

Ref.

Living with

0.26 (0.06-1.19)

0.081

$0.25(0.05-1.25)$

0.091

children

No

Ref.

Yes

$0.77(0.27-2.27)$

0.641

Living with

persons with

comorbidities

No

Ref.

Yes

$0.56(0.16-2.04)$

0.379

Medication

Mesalamine

No

Ref.

Yes

$1.36(0.47-3.98)$

0.571

$\begin{array}{ccc}\begin{array}{c}\text { Corticosteroids } \\ \text { No }\end{array} & \text { Ref. } & \\ \text { Yes } & 1.91(0.50-7.32) & 0.344\end{array}$

Immunomodulators

(azathioprine or 6-

mercaptopurine) No

Ref.

Ref.

Yes

$0.13(0.02-0.98)$

0.048

$0.08(0.01-0.66)$

0.019

\begin{tabular}{ccc}
$\begin{array}{c}\text { Anti-TNF } \\
\text { therapy } \\
\text { No }\end{array}$ & Ref. & \\
Yes & $1.30(0.47-3.63)$ & 0.616 \\
\hline $\begin{array}{c}\text { Ustekinumab } \\
\text { No }\end{array}$ & Ref. & \\
Yes & $2.09(0.63-6.96)$ & 0.229 \\
\hline
\end{tabular}

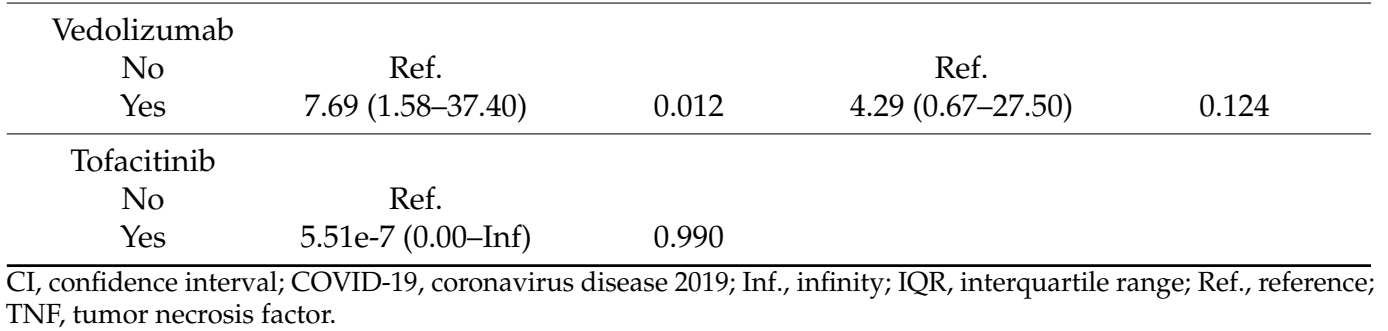

TNF, tumor necrosis factor. 


\subsection{Reasons for COVID-19 Vaccine Hesitancy among Patients with IBD}

Among patients with IBD, COVID-19 vaccine hesitancy was due to concerns about the long-term safety of the vaccines $(n=7)$, possible adverse interaction with immunosuppressive therapies $(n=7)$, lack of trust regarding vaccine development or the testing process $(n=3)$, and concerns about short-term adverse reactions $(n=2)$ (Table 3$)$. The reasons for accepting COVID-19 vaccines are summarized in Table 4.

Table 3. Reasons for COVID-19 vaccination hesitancy.

\begin{tabular}{cc}
\hline Reasons for Hesitating to Get Vaccinated & $\boldsymbol{n ( \% )}$ \\
\hline Concerned that Long-Term Safety of Vaccines & $7(36.8 \%)$ \\
is Unknown & $7(36.8 \%)$ \\
Receiving immunosuppressive therapy & $3(15.8 \%)$ \\
Lack of trust regarding vaccine development or & testing process \\
Concerned about short-term adverse reaction & $2(10.5 \%)$ \\
\hline
\end{tabular}
COVID-19, coronavirus disease 2019.

Table 4. Reasons for the acceptance of COVID-19 vaccination.

\begin{tabular}{cc}
\hline Reasons for Wanting to Be Vaccinated & $\boldsymbol{n} \mathbf{( \% )}$ \\
\hline Acquiring immunity against COVID-19 & $77(45.8 \%)$ \\
Protecting others from COVID-19 & $42(25.0 \%)$ \\
Increased risk of severe COVID-19 due to old & $21(12.5 \%)$ \\
age or comorbidities & $13(7.7 \%)$ \\
Receiving immunosuppressive therapy & $8(4.8 \%)$ \\
Desire to return to normal life & $4(2.4 \%)$ \\
Acquiring herd immunity & $2(1.2 \%)$ \\
Recommendation from physician & $1(0.6 \%)$ \\
Low incidence of adverse effects &
\end{tabular}

COVID-19, coronavirus disease 2019.

\section{Discussion}

\subsection{Hesitancy and Acceptance of OCIVD-19 in Patients with IBD}

The acceptance of patients with IBD to be vaccinated against COVID-19 has not been sufficiently evaluated and the reason for COVID-19 vaccine hesitancy among patients with IBD has not been well understood. We analyzed data from 187 patients with IBD to identify their COVID-19 vaccination intentions and their rationale. We found that $10.2 \%$ of patients with IBD were hesitant to get vaccinated against COVID-19, and the significantly associated factors in the adjusted analysis were the use of immunomodulators and younger age.

Regarding the use of immunomodulators, patients who were not taking immunomodulators might be more likely to be hesitant to use the vaccine. Among the 19 patients in the vaccine-hesitant group, seven patients replied that this was due to their receiving immunosuppressive therapies (Table 3). Among these seven patients, none received immunomodulators, three received corticosteroids, two received TNF therapies, and two received vedolizumab. Patients hesitant to receive vaccines due to immunosuppressive states might think that immunosuppressive drugs could reduce the effectiveness of the vaccines. They might misunderstand that the COVID-19 vaccine was contraindicated, similar to live vaccines. However, COVID-19 vaccination is recommended even for patients with IBD receiving immunosuppressive therapies [31,32]. Of the 187 patients in the vaccine acceptance group, 13 patients replied that the acceptance of vaccination was due to receiving immunosuppressive therapies. However, the number of participants with immunomodulators is very limited and further research would be needed to conclude this. Physicians should inform patients about the necessity of vaccination with immunomodulators and should alleviate their fears.

In contrast, the use of vedolizumab would be a confounding factor for vaccine hesitancy. Vedolizumab was prescribed more frequently in the hesitant group $(p=0.024)$ and 
from the univariate logistic regression analysis, vaccine hesitancy exhibited a significant relationship with the use of vedolizumab (OR: 7.69, 95\% CI: $1.58-37.40, p=0.012$ ). However, patients with vedolizumab therapy were significantly younger compared with patients without vedolizumab therapy $(p=0.037)$ and multivariable logistic regression analysis did not identify the use of vedolizumab as an independent factor for vaccine hesitancy.

The younger generation has been reported to be more likely to refuse the vaccine [7,9]. This is in accordance with the results of this study. Galle et al. [46] reported that age and sex were not significantly associated with vaccine acceptance in the multivariable analysis. The lack of association with age was probably because the age range of their study sample was too narrow to detect an age difference. Several studies have reported factors related to vaccine hesitancy, such as age, sex, income, and education $[5,6,43]$. In this study, we could not evaluate the influence of income and education on vaccine acceptance because the questionnaire did not include questions on these factors. Regarding sex, no statistically significant differences in vaccine hesitancy were noted between males and females, but this may be due to the small sample size.

It is unclear whether patients with IBD are more or less willing to be vaccinated than members of the general population. In one study, patients with IBD were reported to be significantly more hesitant to be vaccinated than control patients without IBD [47]; however, in another study, Dalal et al. [42] reported that willingness to be vaccinated against COVID-19 was higher in patients with IBD than expected based on surveys of the general population in the United States. Our findings suggest that the proportion of patients with IBD who are hesitant about vaccination against COVID-19 vaccine is similar to that of the general population, as reported in different Japanese studies [6-8]. This prevalence of vaccine hesitancy in this study was relatively low compared with that in previous reports of patients with IBD $[40,42]$. This could be due to the timing of the study because COVID-19 has become recognized as a long-term issue and the high effectiveness and safety of vaccination have been widely recognized, although intentions vary widely according to the characteristics of the patient sample, country, and time period [6,48-50].

The majority of patients with severe COVID-19 have at least one comorbidity [51]. Specific risk factors for severe COVID-19 include older age, diabetes, cardiovascular disease, chronic kidney disease, and obstructive pulmonary disease [52]. IBD has not been reported to be associated with an increased risk of severe COVID-19; however, Brenner et al. [53] reported that a higher proportion of patients with IBD who were on steroid treatment required mechanical ventilation or intensive care unit admission and that patients on steroids had higher mortality than patients on other medications. Patients with IBD, who are more likely to require treatment with steroids, should be especially careful to avoid SARS-CoV-2 infection. The long-term side effects of the mRNA vaccines are not yet known; however, achieving an adequate COVID-19 vaccination rate is essential to avoid SARS-CoV2 infection in patients with IBD. Patients, especially young patients and those receiving immunosuppressive therapies, need to be informed of the importance of vaccination. Doctors' recommendations and explanations may assist patients who are hesitant to be vaccinated against COVID-19 to be more receptive to COVID-19 vaccination.

\subsection{Study Limitations}

This study has some limitations including its single-center nature and relatively small sample size. First, this study may have had some selection bias because it was conducted in a single tertiary center. Study participants may have had more complicated disease than IBD patients in general. However, we perform medical follow-up of patients even if they are in remission, so this is unlikely to have had a major effect on the generalizability of the findings. There may also have been participation (self-selection) bias. The prevalence of vaccine hesitancy may have differed among patients who declined to participate. Furthermore, this questionnaire did not include other factors, such as daily habits, educational level, or income [6-8], as this was made to be simple and easy to answer. Additionally, as a cross-sectional design was used, a causal relationship could not be inferred. 


\subsection{Future Research}

Despite these limitations, our findings are unique in that they are the first to report on COVID-19 vaccine intent among patients with IBD in Japan. Appropriate instructions are needed for patients with IBD especially in young patients and patients using immunosuppressive drugs. Physicians' assistance may be required to improve the vaccination rate among patients with IBD. Vaccination rates are rising worldwide but have already peaked in many countries and additional measures may be needed to further increase vaccination coverage.

\section{Conclusions}

\subsection{Acceptance of COVID-19 Vaccine}

This is the first study to access COVID-19 vaccine hesitancy among patients with IBD in Japan. The acceptance of COVID-19 vaccine in patients with IBD in Japan was relatively high compared to that reported in previous studies. This study indicates factors associated with COVID-19 acceptance were older age and the use of immunomodulators (azathioprine or 6-mercaptopurine). However, this study design had a single-center nature and a relatively small sample size. Further study would be needed to conclude this.

\subsection{Practical Implications}

The theoretical safety of the. mRNA vaccine during immunomodulator use, evidencebased safety, and patient education with correct information could contribute toward the improvement of the vaccination rate. It is necessary to explain to patients that the benefits of vaccines outweigh the disadvantages, especially in patients without immunomodulators and young patients. Further efforts should be made to protect patients with IBD from SARS-CoV-2 infection and to achieve adequate vaccination coverage.

Supplementary Materials: The following are available online at https://www.mdpi.com/article/10 $.3390 /$ healthcare10010006/s1, Table S1: questionnaire.

Author Contributions: Conceptualization, Y.N. (Yu Nishida) and S.H.; methodology, Y.N. (Yu Nishida) and S.H.; formal analysis, Y.N. (Yu Nishida) and S.H.; investigation, Y.N. (Yu Nishida) and S.H.; writing-original draft preparation, Y.N. (Yu Nishida); writing-review and editing, S.H., Y.K., R.N., M.O., Y.N. (Yuji Nadatani), S.F., K.O., F.T., Y.N. (Yasuaki Nagami), K.T., N.K. and Y.F. All authors have read and agreed to the published version of the manuscript.

Funding: This research received no external funding.

Institutional Review Board Statement: The study was conducted according to the guidelines of the Declaration of Helsinki, and approved by the Ethics Review Board of Osaka City University Graduate School of Medicine approved this study (no. 2021-102).

Informed Consent Statement: Informed consent was obtained from all subjects involved in the study. All participants had to provide their consent before they proceeded to the questionnaire response page. The questionnaires were made anonymous to ensure patient privacy.

Data Availability Statement: The data presented in this study are available on request from the corresponding author. The data are not publicly available due to privacy restrictions.

Conflicts of Interest: The authors declare no conflict of interest.

\section{References}

1. Wang, C.; Horby, P.W.; Hayden, F.G.; Gao, G.F. A novel coronavirus outbreak of global health concern. Lancet 2020, 395, 470-473. [CrossRef]

2. Polack, F.P.; Thomas, S.J.; Kitchin, N.; Absalon, J.; Gurtman, A.; Lockhart, S.; Perez, J.L.; Pérez Marc, G.; Moreira, E.D.; Zerbini, C.; et al. Safety and Efficacy of the BNT162b2 mRNA COVID-19 Vaccine. N. Engl. J. Med. 2020, 383, 2603-2615. [CrossRef] [PubMed]

3. Zhu, F.C.; Li, Y.H.; Guan, X.H.; Hou, L.H.; Wang, W.J.; Li, J.X.; Wu, S.P.; Wang, B.S.; Wang, Z.; Wang, L.; et al. Safety, tolerability, and immunogenicity of a recombinant adenovirus type-5 vectored COVID-19 vaccine: A dose-escalation, open-label, non-randomised, first-in-human trial. Lancet 2020, 395, 1845-1854. [CrossRef]

4. Troiano, G.; Nardi, A. Vaccine hesitancy in the era of COVID-19. Public Health 2021, 194, 245-251. [CrossRef] [PubMed] 
5. Robinson, E.; Jones, A.; Lesser, I.; Daly, M. International estimates of intended uptake and refusal of COVID-19 vaccines: A rapid systematic review and meta-analysis of large nationally representative samples. Vaccine 2021, 39, 2024-2034. [CrossRef] [PubMed]

6. Nomura, S.; Eguchi, A.; Yoneoka, D.; Kawashima, T.; Tanoue, Y.; Murakami, M.; Sakamoto, H.; Maruyama-Sakurai, K.; Gilmour S.; Shi, S.; et al. Reasons for being unsure or unwilling regarding intention to take COVID-19 vaccine among Japanese people: A large cross-sectional national survey. Lancet Reg. Health. West. Pac. 2021, 14, 100223. [CrossRef]

7. Yoda, T.; Katsuyama, H. Willingness to Receive COVID-19 Vaccination in Japan. Vaccines 2021, 9, 48. [CrossRef]

8. Okubo, R.; Yoshioka, T.; Ohfuji, S.; Matsuo, T.; Tabuchi, T. COVID-19 Vaccine Hesitancy and Its Associated Factors in Japan. Vaccines 2021, 9, 662. [CrossRef] [PubMed]

9. Muto, K.; Yamamoto, I.; Nagasu, M.; Tanaka, M.; Wada, K. Japanese citizens' behavioral changes and preparedness against COVID-19: An online survey during the early phase of the pandemic. PLoS ONE 2020, 15, e0234292. [CrossRef]

10. Heidari, S.; Palmer-Ross, A.; Goodman, T. A Systematic Review of the Sex and Gender Reporting in COVID-19 Clinical Trials. Vaccines 2021, 9, 1322. [CrossRef]

11. Salomoni, M.G.; Di Valerio, Z.; Gabrielli, E.; Montalti, M.; Tedesco, D.; Guaraldi, F.; Gori, D. Hesitant or Not Hesitant? A Systematic Review on Global COVID-19 Vaccine Acceptance in Different Populations. Vaccines 2021, 9, 873. [CrossRef]

12. Sallam, M. COVID-19 Vaccine Hesitancy Worldwide: A Concise Systematic Review of Vaccine Acceptance Rates. Vaccines 2021, 9 , 160. [CrossRef]

13. Aw, J.; Seng, J.J.B.; Seah, S.S.Y.; Low, L.L. COVID-19 Vaccine Hesitancy-A Scoping Review of Literature in High-Income Countries. Vaccines 2021, 9, 900. [CrossRef]

14. Joshi, A.; Kaur, M.; Kaur, R.; Grover, A.; Nash, D.; El-Mohandes, A. Predictors of COVID-19 Vaccine Acceptance, Intention, and Hesitancy: A Scoping Review. Front. Public Health 2021, 9, 698111. [CrossRef]

15. Ananthakrishnan, A.N. Epidemiology and risk factors for IBD. Nat. Rev. Gastroenterol. Hepatol. 2015, 12, 205-217. [CrossRef]

16. Ranjbaran, Z.; Keefer, L.; Farhadi, A.; Stepanski, E.; Sedghi, S.; Keshavarzian, A. Impact of sleep disturbances in inflammatory bowel disease. J. Gastroenterol. Hepatol. 2007, 22, 1748-1753. [CrossRef]

17. Ali, T.; Madhoun, M.F.; Orr, W.C.; Rubin, D.T. Assessment of the relationship between quality of sleep and disease activity in inflammatory bowel disease patients. Inflamm. Bowel Dis. 2013, 19, 2440-2443. [CrossRef]

18. Saadoune, N.; Peyrin-Biroulet, L.; Baumann, C.; Bigard, M.A.; Wirth, N.; Martinet, Y.; Peyrin-Biroulet, C. Beliefs and behaviour about smoking among inflammatory bowel disease patients. Eur. J. Gastroenterol. Hepatol. 2015, 27, 797-803. [CrossRef]

19. Uemura, R.; Fujiwara, Y.; Iwakura, N.; Shiba, M.; Watanabe, K.; Kamata, N.; Yamagami, H.; Tanigawa, T.; Watanabe, T.; Tominaga, K.; et al. Sleep disturbances in Japanese patients with inflammatory bowel disease and their impact on disease flare. SpringerPlus 2016, 5, 1792. [CrossRef]

20. Kirchgesner, J.; Lemaitre, M.; Carrat, F.; Zureik, M.; Carbonnel, F.; Dray-Spira, R. Risk of Serious and Opportunistic Infections Associated With Treatment of Inflammatory Bowel Diseases. Gastroenterology 2018, 155, 337-346. [CrossRef]

21. Lichtenstein, G.R.; Feagan, B.G.; Cohen, R.D.; Salzberg, B.A.; Diamond, R.H.; Price, S.; Langholff, W.; Londhe, A.; Sandborn, W.J. Serious infection and mortality in patients with Crohn's disease: More than 5 years of follow-up in the TREATTM registry. Am. J. Gastroenterol. 2012, 107, 1409-1422. [CrossRef]

22. Nishida, Y.; Hosomi, S.; Fujimoto, K.; Nakata, R.; Sugita, N.; Itani, S.; Nadatani, Y.; Fukunaga, S.; Otani, K.; Tanaka, F.; et al. Impact of the Lockdown Due to the COVID-19 Pandemic on Patients With Inflammatory Bowel Disease. Front. Med. 2021, 8. [CrossRef]

23. Trindade, I.A.; Ferreira, N.B. COVID-19 Pandemic's Effects on Disease and Psychological Outcomes of People With Inflammatory Bowel Disease in Portugal: A Preliminary Research. Inflamm. Bowel Dis. 2021, 27, 1224-1229. [CrossRef]

24. Chan, W.; Salazar, E.; Lim, T.G.; Ong, W.C.; Shim, H.H. Vaccinations and inflammatory bowel disease-A systematic review. Dig. Liver Dis. 2021, 53, 1079-1088. [CrossRef]

25. Monteleone, G.; Ardizzone, S. Are Patients with Inflammatory Bowel Disease at Increased Risk for COVID-19 Infection? J. Crohn's Colitis 2020, 14, 1334-1336. [CrossRef] [PubMed]

26. Rubin, D.T.; Feuerstein, J.D.; Wang, A.Y.; Cohen, R.D. AGA Clinical Practice Update on Management of Inflammatory Bowel Disease During the COVID-19 Pandemic: Expert Commentary. Gastroenterology 2020, 159, 350-357. [CrossRef] [PubMed]

27. Magro, F.; Rahier, J.F.; Abreu, C.; MacMahon, E.; Hart, A.; van der Woude, C.J.; Gordon, H.; Adamina, M.; Viget, N.; Vavricka, S.; et al. Inflammatory Bowel Disease Management During the COVID-19 Outbreak: The Ten Do's and Don'ts from the ECCO-COVID Taskforce. J. Crohn's Colitis 2020, 14, S798-S806. [CrossRef] [PubMed]

28. Hadi, Y.B.; Thakkar, S.; Shah-Khan, S.M.; Hutson, W.; Sarwari, A.; Singh, S. COVID-19 Vaccination Is Safe and Effective in Patients With Inflammatory Bowel Disease: Analysis of a Large Multi-institutional Research Network in the United States. Gastroenterology 2021, 161, 1336-1339. [CrossRef]

29. Singh, A.K.; Jena, A.; Kumar, M.P.; Sharma, V.; Sebastian, S. Risk and outcomes of coronavirus disease in patients with inflammatory bowel disease: A systematic review and meta-analysis. United Eur. Gastroenterol. J. 2021, 9, 159-176. [CrossRef]

30. Severity of COVID-19 and survival in patients with rheumatic and inflammatory diseases: Data from the French RMD COVID-19 cohort of 694 patients. Ann. Rheum. Dis. 2020, 80, 527-538. [CrossRef]

31. Siegel, C.A.; Melmed, G.Y.; McGovern, D.P.; Rai, V.; Krammer, F.; Rubin, D.T.; Abreu, M.T.; Dubinsky, M.C. SARS-CoV-2 vaccination for patients with inflammatory bowel diseases: Recommendations from an international consensus meeting. Gut 2021, 70, 635-640. [CrossRef] 
32. Alexander, J.L.; Moran, G.W.; Gaya, D.R.; Raine, T.; Hart, A.; Kennedy, N.A.; Lindsay, J.O.; MacDonald, J.; Segal, J.P.; Sebastian, S.; et al. SARS-CoV-2 vaccination for patients with inflammatory bowel disease: A British Society of Gastroenterology Inflammatory Bowel Disease section and IBD Clinical Research Group position statement. Lancet. Gastroenterol. Hepatol. 2021, 6, 218-224. [CrossRef]

33. Jena, A.; Mishra, S.; Deepak, P.; Kumar, M.P.; Sharma, A.; Patel, Y.I.; Kennedy, N.A.; Kim, A.H.J.; Sharma, V.; Sebastian, S. Response to SARS-CoV-2 vaccination in immune mediated inflammatory diseases: Systematic review and meta-analysis. Autoimmun. Rev. 2021, 30, 102927. [CrossRef]

34. Firinu, D.; Perra, A.; Campagna, M.; Littera, R.; Fenu, G.; Meloni, F.; Cipri, S.; Sedda, F.; Conti, M.; Miglianti, M.; et al. Evaluation of antibody response to BNT162b2 mRNA COVID-19 vaccine in patients affected by immune-mediated inflammatory diseases up to 5 months after vaccination. Clin. Exp. Med. 2021, 5, 1-9. [CrossRef]

35. Sakuraba, A.; Luna, A.; Micic, D. Serologic Response to Coronavirus Disease 2019 (COVID-19) Vaccination in Patients With Immune-Mediated Inflammatory Diseases: A Systematic Review and Meta-analysis. Gastroenterology 2021, 162, 88-108. [CrossRef]

36. Wyant, T.; Leach, T.; Sankoh, S.; Wang, Y.; Paolino, J.; Pasetti, M.F.; Feagan, B.G.; Parikh, A. Vedolizumab affects antibody responses to immunisation selectively in the gastrointestinal tract: Randomised controlled trial results. Gut 2015, 64, 77-83. [CrossRef]

37. Colombel, J.F.; Sands, B.E.; Rutgeerts, P.; Sandborn, W.; Danese, S.; D’Haens, G.; Panaccione, R.; Loftus, E.V., Jr.; Sankoh, S.; Fox, I.; et al. The safety of vedolizumab for ulcerative colitis and Crohn's disease. Gut 2017, 66, 839-851. [CrossRef]

38. Kennedy, N.A.; Lin, S.; Goodhand, J.R.; Chanchlani, N.; Hamilton, B.; Bewshea, C.; Nice, R.; Chee, D.; Cummings, J.F.; Fraser, A.; et al. Infliximab is associated with attenuated immunogenicity to BNT162b2 and ChAdOx1 nCoV-19 SARS-CoV-2 vaccines in patients with IBD. Gut 2021, 70, 1884-1893. [CrossRef]

39. Costantino, A.; Noviello, D.; Conforti, F.S.; Aloi, M.; Armuzzi, A.; Bossa, F.; Ficari, F.; Leone, S.; Manguso, F.; Mocci, G.; et al. COVID-19 Vaccination Willingness and Hesitancy in Patients With Inflammatory Bowel Diseases: Analysis of Determinants in a National Survey of the Italian IBD Patients' Association. Inflamm. Bowel Dis. 2021. Online ahead of print. [CrossRef]

40. Caron, B.; Neuville, E.; Peyrin-Biroulet, L. Inflammatory Bowel Disease and COVID-19 Vaccination: A Patients' Survey. Dig. Dis. Sci. 2021, 12, 1-7. [CrossRef]

41. Ferreiro-Iglesias, R.; Hernández-Camba, A.; Serrano Labajos, R.; Rodríguez-Lago, I.; Zabana, Y.; Barreiro-de Acosta, M. SARS$\mathrm{CoV}-2$ vaccine acceptance among gastroenterologists and inflammatory bowel disease patients: VACUNEII project. Gastroenterol. Hepatol. 2021. [CrossRef] [PubMed]

42. Dalal, R.S.; McClure, E.; Marcus, J.; Winter, R.W.; Hamilton, M.J.; Allegretti, J.R. COVID-19 Vaccination Intent and Perceptions Among Patients With Inflammatory Bowel Diseases. Clin. Gastroenterol. Hepatol. 2021, 19, 1730-1732. [CrossRef] [PubMed]

43. Machida, M.; Nakamura, I.; Kojima, T.; Saito, R.; Nakaya, T.; Hanibuchi, T.; Takamiya, T.; Odagiri, Y.; Fukushima, N.; Kikuchi, H.; et al. Acceptance of a COVID-19 Vaccine in Japan during the COVID-19 Pandemic. Vaccines 2021, 9, 210. [CrossRef] [PubMed]

44. Tabacchi, G.; Costantino, C.; Cracchiolo, M.; Ferro, A.; Marchese, V.; Napoli, G.; Palmeri, S.; Raia, D.; Restivo, V.; Siddu, A.; et al. Information sources and knowledge on vaccination in a population from southern Italy: The ESCULAPIO project. Hum. Vaccines Immunother. 2017, 13, 339-345. [CrossRef] [PubMed]

45. Harris, P.A.; Taylor, R.; Thielke, R.; Payne, J.; Gonzalez, N.; Conde, J.G. Research electronic data capture (REDCap)—A metadatadriven methodology and workflow process for providing translational research informatics support. J. Biomed. Inform. 2009, 42, 377-381. [CrossRef] [PubMed]

46. Gallè, F.; Sabella, E.A.; Roma, P.; De Giglio, O.; Caggiano, G.; Tafuri, S.; Da Molin, G.; Ferracuti, S.; Montagna, M.T.; Liguori, G.; et al. Knowledge and Acceptance of COVID-19 Vaccination among Undergraduate Students from Central and Southern Italy. Vaccines 2021, 9, 638. [CrossRef] [PubMed]

47. Walldorf, J.; von Arnim, U.; Schmelz, R.; Riesner-Wehner, A.; Michl, P.; Grunert, P.C.; Stallmach, A.; Teich, N.; Reuken, P.A. SARS-CoV-2 Vaccination in Patients With Inflammatory Bowel Disease-Fear and Desire. Inflamm. Bowel Dis. 2021, 27, 1858-1861. [CrossRef]

48. Lazarus, J.V.; Ratzan, S.C.; Palayew, A.; Gostin, L.O.; Larson, H.J.; Rabin, K.; Kimball, S.; El-Mohandes, A. A global survey of potential acceptance of a COVID-19 vaccine. Nat. Med. 2021, 27, 225-228. [CrossRef]

49. Reiter, P.L.; Pennell, M.L.; Katz, M.L. Acceptability of a COVID-19 vaccine among adults in the United States: How many people would get vaccinated? Vaccine 2020, 38, 6500-6507. [CrossRef]

50. Ward, J.K.; Alleaume, C.; Peretti-Watel, P. The French public's attitudes to a future COVID-19 vaccine: The politicization of a public health issue. Soc. Sci. Med. 2020, 265, 113414. [CrossRef]

51. Preliminary Estimates of the Prevalence of Selected Underlying Health Conditions Among Patients with Coronavirus Disease 2019-United States, February 12-March 28, 2020. MMWR. Morb. Mortal. Wkly. Rep. 2020, 69, 382-386. [CrossRef]

52. Wu, C.; Chen, X.; Cai, Y.; Xia, J.; Zhou, X.; Xu, S.; Huang, H.; Zhang, L.; Zhou, X.; Du, C.; et al. Risk Factors Associated With Acute Respiratory Distress Syndrome and Death in Patients With Coronavirus Disease 2019 Pneumonia in Wuhan, China. JAMA Intern. Med. 2020, 180, 934-943. [CrossRef]

53. Brenner, E.J.; Ungaro, R.C.; Gearry, R.B.; Kaplan, G.G.; Kissous-Hunt, M.; Lewis, J.D.; Ng, S.C.; Rahier, J.F.; Reinisch, W.; Ruemmele, F.M.; et al. Corticosteroids, But Not TNF Antagonists, Are Associated With Adverse COVID-19 Outcomes in Patients With Inflammatory Bowel Diseases: Results From an International Registry. Gastroenterology 2020, 159, 481-491. [CrossRef] 